\title{
THE STRUCTURE AND SYSTEMATIC IMPORTANCE OF THE SPERMATOPHORES OF CRICKETS.
}

\author{
J. P. Jensen.
}

In several groups of animals, we find that the spermatozoa are held in packets or masses, and in some such as the Cephalopods, there is high specialization of the spermatophore, as the organ is called, in which the spermatozoa are contained. Among the insects, only representatives of a few groups form spermatophores, but when present they are beautiful and interesting structures and those formed by the gryllids or crickets are especially so.

While engaged in research work on crickets in the Entomological Laboratory of Cornell University, I noticed one day that a female Gryllus had a small pear-shaped organ attached between the ventral surface of the base of the ovipositor and the posterior end of the 8th abdominal sternite (Fig. 1). This structure did not seem to be part of her own body and as I did not at the time know anything about spermatophores, I was very much puzzled by it. After investigating the literature I found that I had happened to collect the specimen before the spermatophore had dropped off, and upon examining several males, I found a similar organ in situ in most of them, just outside of what was considered the genital opening and covered by the ends of the posterior sclerites.

Crickets, such as members of the genera Gryllus, Nemobius and Oecanthus are very difficult to classify and I had encountered considerable difficulty in obtaining good specific characters. More with a view of determining whether the spermatophores might not assist me in classifying them, than expecting to make any morphological discoveries, I commenced to study them somewhat thoroughly.

The literature was searched for accounts of copulation in these and related insects and five references were found. Serville stated that in copulation the female Gryllus mounts the body of the male, as in the Oecanthids. Peytoureau said that in the Locustidae the transfer of spermatozoa takes place by means of a pear-shaped spermatophore that is transferred to the 
female in copulation. Packard mentioned that in the two families of Gryllidae and Locustidae this was true and that especially Gryllus had been noticed to have this habit. Gillette in 1904 gave an excellent illustrated account of the structure and transfer of the spermatophores of the Western Cricket, Anabrus simplex, family Locustidae, and the most complete was found to be an account by Lespes in 1855 , who not only noticed carefully the complete process of copulation but by dissection he determined how the spermatophores were developed and to some extent the function of the parts of the spermatophore.

After relaxing some of my specimens of Gryllus, I dissected out the spermatophores in several males to gain a good knowledge of their structure. The spermatophore proper (Fig. 2, A) is attached to a handle-shaped part (Fig. 2, B) possessing five lateral hooks, three in front and two behind. The function of these hooks was not understood at the time but will appear later. A long whip-like part (Fig. 2, C) is attached to the dorsal side of the handle. Many males were examined and a spermatophore was almost always found present. This is in accordance with Lespes' observations, who found that a new spermatophore was completely formed in about one hour and that each female copulated several times during the egg-laying season.

To determine the function of the parts, the female that had this organ still attached was after relaxation carefully dissected. The function of the hooks on the handle was readily found to be for attachment. The anterior part of the handle was found to be inside of the vaginal opening and the three anterior hooks held it firmly in place. The two at the posterior end also curve up and serve to hold it firmly in place by clasping to some extent the basal part of the ovipositor. After removing the bulb of the spermatophore, I attempted to remove the handle, but the anterior hooks held too firmly, part of it broke off but the whiplike structure remained attached and when pulled out, showed that it had extended a considerable distance up the passage and as will soon be shown this would indicate that the spermatheca is quite far removed from the external opening. By mounting in glycerine and using high power the true relation of the whip-like part to the handle was made out, and also the nature and function of the former structure. It is attached somewhat nearer the spermatophore body than the middle of 
the handle and is continued as a dorsal thickening of the handle into the narrow cylindrical attachment between the handle and the bulb. It is in fact a duct, whose cavity can be traced from a point some distance inside the bulb (Fig. 2, D) to its outlet at the end of the whip.

This was proven by embedding the tiny structure in paraffin and taking microtome sections of it (Fig. 3 and 4), from the farther end of the handle to almost the tip of the thread. The outside wall is rather gelatinous and soft, but a cylindrical, central core (Figs. 3 and 4, B) of very hard, apparently chitinous, material has the tiny duct in its center (Figs. 3 and $4, \mathrm{C}$ ) and in the sections this duct had not been flattened in the least. The very firm walls are no doubt for the purpose of preventing flattening or deformation, which might compress the duct and prevent the passage of the spermatozoa.

Last summer I again had opportunity to witness the courting and mating of Oecanthis fasciatus, and the process was very much the same as described by the writer in the Canadian Entomologist, Jan., '09. Then, however, I had missed the transfer of the spermatophore and after killing this female I removed the organ and mounted it in the usual way under a cover glass in canada balsam. Watching it under low power of the microscope I succeeded by judicious pressure, in causing the spermatozoa to flow out of the end of the "thread." This was final proof that this part of the organ is for conducting the spermatozoa to the spermatheca. Lespes in his account, somehow seems to have overlooked the fact that this thread-like structure is a duct, likely due to the minuteness of the duct itself, which when highly magnified, reminds one of a fine capillary tube. He calls it a horny thread, "file corné." In fact he does not attempt to explain the structure at all, nor how the spermatozoa enter the vagina of the female from the spermatophore after it has been placed in position.

As before mentioned, the various species of crickets are very difficult to determine and the spermatophores may in the future be of considerable importance for definitely defining the species. For instance, Minnesota specimens of Gryllus pennsylvanicus Burm. vary considerably in general coloration and size from the Eastern specimens, but the spermatophores examined were all exactly alike. Lespes described and figured the respective spermatophores of the common European species, Gryllus 
sylvestris, G. campestris and G. domesticus, and they differ very markedly from one another. Oecanthis fasciatus Fitch and $\mathrm{O}$. quadripunctatus Beut. are the same species as gradations in the antennal markings show very nicely when one has considerable material. Whether the spermatophores further verify this, I have not as yet been able to definitely determine but it appears to me that the spermatophores of insects are worthy of considerable more attention than has been devoted to them in the past.

\section{EXPLANATION OF PLATE V.}

All figures magnified, 3 and 4 highly.

FIG. 1. Attachment of spermatophore to female Gryllus pennsylvanicus. A, bulb of spermatophore; B, Sth abdominal sternite; C, ovipositor.

FIG. 2. Spermatophore of G. pennsylvanicus, magnified. A, bulb; B. handle; C, thread-like part (Lespes "file corne"); D, duct; E, cross-section shown in Fig. 3; F, cross-section shown in Fig. 4.

Figs. 3 and 4. Cross-sections of thread at $\mathrm{E}$ and $\mathrm{F}$ in Fig. 2. A, gelatinous outside wall; $\mathrm{B}$, hard core; $\mathrm{C}$, duct. 

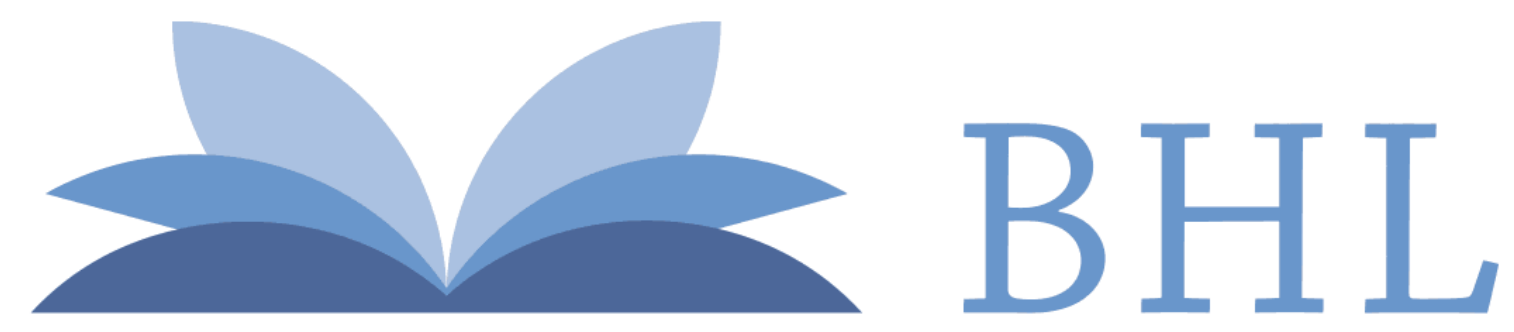

\section{Biodiversity Heritage Library}

Jensen, J P . 1911. "The Structure and Systematic Importance of the Spermatophores of Crickets." Annals of the Entomological Society of America 4, 63-66. https://doi.org/10.1093/aesa/4.1.63.

View This Item Online: https://www.biodiversitylibrary.org/item/54996

DOI: https://doi.org/10.1093/aesa/4.1.63

Permalink: https://www.biodiversitylibrary.org/partpdf/193794

\section{Holding Institution}

Smithsonian Libraries

\section{Sponsored by}

Smithsonian

\section{Copyright \& Reuse}

Copyright Status: Public domain. The BHL considers that this work is no longer under copyright protection.

This document was created from content at the Biodiversity Heritage Library, the world's largest open access digital library for biodiversity literature and archives. Visit BHL at https://www.biodiversitylibrary.org. 